This is a post-peer-review, pre-copyedit version of an article published in GPS Solutions. The final authenticated version is available online at: https://doi.org/10.1007/s10291-019-0882-7.

\title{
4 Signal analysis of the first GPS III satellite
}

$5 \quad$ Steffen Thoelert ${ }^{1)}$, Peter Steigenberger $^{2)}$, Oliver Montenbruck $^{2)}$, Michael Meurer $^{1)}$

1) Deutsches Zentrum für Luft- und Raumfahrt, Institute of Communications and Navigation, 82234 Wessling,

7 Germany

${ }^{2)}$ Deutsches Zentrum für Luft- und Raumfahrt, German Space Operations Center, 82234 Wessling, Germany

10 Steffen Thoelert, steffen.thoelert@dlr.de, ORCID 0000-0003-4653-318X

11 Peter Steigenberger, peter.steigenberger@dlr.de, ORCID 0000-0003-1905-6699

12 Oliver Montenbruck, oliver.montenbruck@dlr.de, ORCID 0000-0003-4783-745X

13 Michael Meurer, michael.meurer@dlr.de, ORCID 0000-0001-7465-6705

\section{Abstract}

16 The signal-in-space of the first GPS Block III spacecraft is analyzed based on radio-frequency measurements collected with a $30 \mathrm{~m}$ high-gain dish antenna as well as data from geodetic GPS receivers. The spectral properties and modulation characteristics are discussed with focus on the L1 band, which employs a novel interlaced majority voting technique for combination of the $\mathrm{C} / \mathrm{A}, \mathrm{P}(\mathrm{Y})$, and $\mathrm{L} 1 \mathrm{C}$ data+pilot signal components. Compared to the preceding generation of Block IIF satellites, a modified shaping of the L1 transmit antenna gain pattern is found, which results in lower carrier-to-noise density ratios at mid to high elevations. Along with this, use of a separate transmission chain for the military M-code signal is evidenced through the analysis of in-phase/quadrature signal components and the derived transmit antenna gain variations. A high level of signal purity is demonstrated on all frequencies, which can be attributed to the use of a new, mostly digital, signal generation unit. Maps of code bias variations for selected signals are presented to quantify the achievable user tracking performance as a function of user receiver parameters. For the L5 signal, a notable reduction of digital distortions is obtained with respect to the Block IIF satellites, whereas analog distortions are found to be of similar magnitude. Thermally induced L5 phase variations found in the Block IIF satellites are no longer observed in GPS III. Using triple-frequency phase observations, a sub-centimeter consistency of the L1, L2, and L5 carriers is demonstrated. 
Space Vehicle Number (SVN) 74 is the first of a new generation of GPS satellites built by Lockheed Martin. The GPS III satellites offer an increased 15-years life time and a wide series of technological improvements over their predecessors, while maintaining compatibility with other satellites in the constellation for navigation users. Among others, the satellites make use of a new, mostly digital, signal generation unit, support up to 64 different ranging codes, host three enhanced rubidium atomic frequency standards, support continuous monitoring of a redundant clock in hot standby, and are equipped with an enhanced cross-link transponder (Marquis and Shaw 2011).

The SVN 74 spacecraft with a wet mass of about 3.7 tons and a dry mass of 2.2 tons was launched with a Falcon 9 rocket from Cape Canaveral, Florida, on December 23, 2018. Following injection into a transfer orbit and performance of several orbit raising maneuvers, the spacecraft arrived near slot " 3 " of orbital plane " $F$ " and started transmission in the L1, L2, and L5 frequency bands in early 2019 (Fig. 1). First signals using the pseudorandom noise (PRN) number 4 ranging codes were tracked by worldwide GPS receivers starting on January 9.

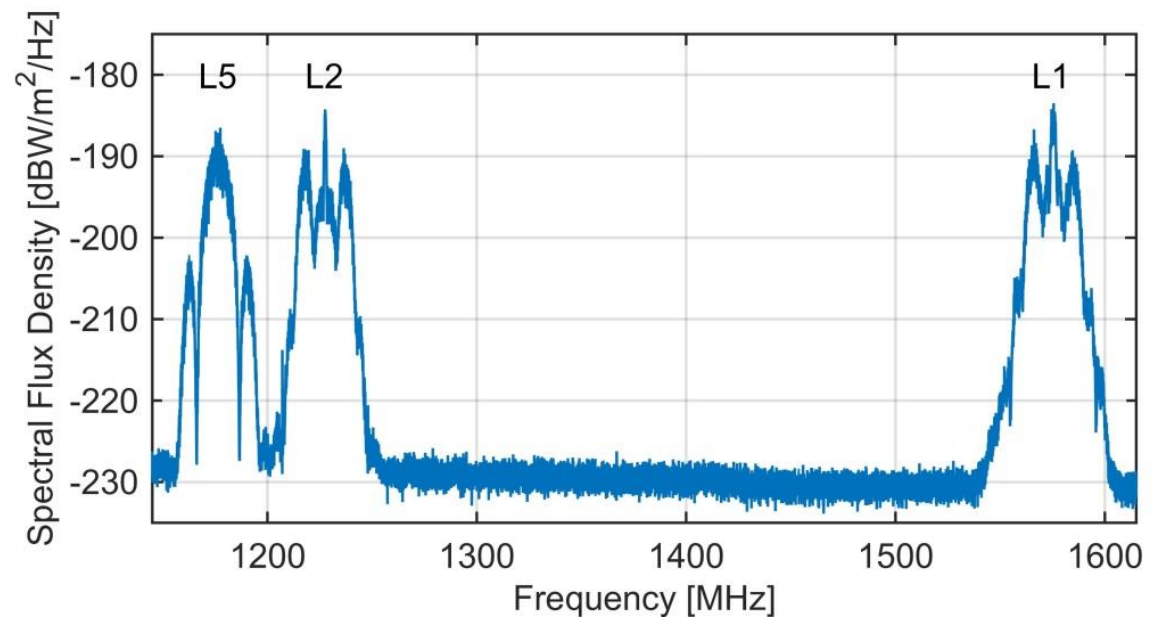

Fig. 1 SVN 74 spectrum recorded with the Weilheim 30 m antenna on January 9, 2019 at 12:40 UTC.

Among the most notable features of the new GPS III satellites is the transmission of a new civil navigation signal, named L1C, on the L1 frequency (IS-GPS-800E, 2018). Compared to the legacy L1 coarse/acquisition (C/A) code, the L1C signal uses the same chipping rate of $1.023 \mathrm{MHz}$ but makes use of 10-times longer ranging codes, provides distinct data and pilot channels, and carries the new CNAV-2 navigation message with forward error correction (Betz et al. 2006). The use of a binary offset carrier $(\operatorname{BOC}(1,1))$ modulation with a square sub-carrier of the same rate as the ranging code results in a split power spectrum and enables good compatibility with other L1 signals. Improved multipath performance is, furthermore, achieved through time multiplexed binary offset carrier (TMBOC $(6,1,4 / 33))$ modulation of the pilot channel, which replaces the BOC $(1,1)$ subcarrier by a BOC $(6,1)$ subcarrier for 4/33th of the time (Chen et al. 2014). Distinct families of Weil codes were selected to achieve optimum cross-correlation properties for both pilot and data channel modulation (Rushanan 2007). Overall, L1C offers more robust navigation under adverse signal conditions such as low power or multipath as well as reduced 
time-to-first fix. It is, furthermore, designed to be fully interoperable with the Galileo E1 Open Service signal (Hein et al. 2006) and the BeiDou B1C signal on the same center frequency.

An early characterization and quality assessment of signals transmitted by the new GPS III satellite within the first month after activation are presented in this work. The results are based on high-gain antenna measurements obtained at the Weilheim signal monitoring facility (Thoelert et al. 2009). With a diameter of $30 \mathrm{~m}$, the antenna offers a total gain of about $50 \mathrm{~dB}$ and enables detailed performance studies in the spectral and temporal domain for all GNSS signals in the lower and upper L-band. Furthermore, absolute power level measurements are supported through regular calibration of the entire measurement system against external standards. Complementary to the signal monitoring facility, observations with geodetic-grade multi-frequency receivers are conducted to assess the SVN 74 tracking performance from a user perspective.

Following the introduction, the article first provides an overview of GPS III signals in the L1, L2, and L5 frequency bands. Specific modulation schemes and differences with respect to previous generations are outlined and illustrated through signal spectra and in-phase and quadrature constellation diagrams. A quantitative performance assessment based on high-gain antenna measurements and receiver tracking data is provided in the subsequent section. It provides an S-curve analysis for evaluation of chip-shape induced code tracking biases, a signal strength characterization, and a comparison of receiver tracking noise and multipath for different signals. Furthermore, the consistency of the L1, L2, and L5 carriers is evaluated using a triple-carrier phase combination.

\section{GPS III signals}

Within this section the GPS III signals are briefly introduced, and basic signal analyses are performed based on spectral and in-phase and quadrature (IQ) measurements.

\section{L1 signal components}

The L1 signal transmitted by the GPS III satellites comprises a notably larger number of individual components than that of past generations. As documented in the US Federal Radionavigation Plan, the US government is committed to continue transmission of the C/A-code and the encrypted $\mathrm{P}(\mathrm{Y})$-code with their current characteristics for up to a minimum of two years after the deployment of a 24-satellites GPS constellation with L5 capability (FRNP 2017). Along with the military M-code signal and the addition of a new civil L1C signal comprising a data (L1C-D) and pilot (L1C-P) component, a total of five navigation signals are now transmitted on the L1 carrier to maintain the desired level of full backwards compatibility (Table 1; Betz 2016). 
Table 1 GPS III L1 signal components

\begin{tabular}{lllll}
\hline Component & Modulation & $\begin{array}{l}\text { Chipping rate } \\
{[\mathrm{MHz}]}\end{array}$ & $\begin{array}{l}\text { Minimum received } \\
\text { power [dBW] }\end{array}$ & Reference \\
\hline C/A & BPSK(1) & 1.023 & -158.5 & IS-GPS-200J (2018) \\
L1C data & BOC $(1,1)$ & 1.023 & -163.0 & IS-GPS-800E (2018) \\
L1C pilot & TMBOC $(6,1,4 / 33)$ & 1.023 & -158.25 & IS-GPS-800E (2018) \\
P(Y) & BPSK $(10)$ & 10.23 & -161.5 & IS-GPS-200J (2018) \\
M & BOC $(10,5)$ & 10.23 & -158.0 & Marquis and Reigh (2015) \\
\hline
\end{tabular}

BPSK: Binary Phase Shift Keying; BOC: Binary Offset Carrier; TMBOC: Time-Multiplexed BOC 2001) that is used in the Block IIR-M and IIF satellites for combining the C/A-, P(Y)- and M-codes with adjustable power levels, a notably different approach is taken in GPS III. First, a distinct amplifier and antenna chain are used for the M-code transmission, which can thus be controlled independently from the four other signal components transmitted via the main L-band antenna. For the remaining four signals, a quadrature phase shift keying (QPSK) modulation is employed with one signal (C/A-code) in the quadrature $(\mathrm{Q})$ channel and an interlaced majority voting combination (Spilker and Orr 1998) of the P(Y) signal along with the L1C data and pilot components in the in-phase (I) channel. Overall, the employed multiplexing scheme offers an efficient constant-envelope modulation of four user signals.

The L1 signal composition is illustrated by the IQ constellation diagram in Fig. 2, which shows the colorcoded amplitude of in-phase and quadrature signal components obtained after down-conversion and Dopplerremoval of the SVN $74 \mathrm{~L} 1$ signal collected with the $30 \mathrm{~m}$ high-gain antenna. The QPSK modulation of C/A-, P(Y)and L1C-codes results in a rectangular set of stationary points, which alternates between two positions in the IQ plane depending on the instantaneous M-code chip and data bit. While the M-code is generated phase-coherently with the other signals, the transmission via a different antenna chain with different phase center results in a phase shift with respect to transitions of the other signals. This phase shift depends on the projection of the relative phase center vector on the line of sight and therefore varies over time along with the varying boresight angle. Different alignments of the M-code transitions with respect to those of the other signals may thus be observed at different measurement epochs. In addition, the relative amplitude of M-code chip transitions varies with the viewing direction due to the different antenna gain patterns. 


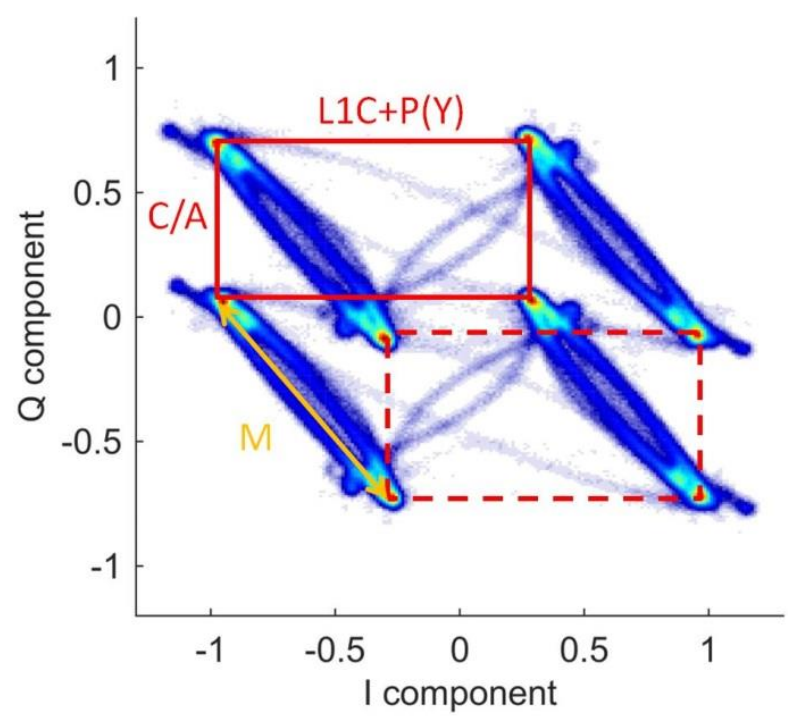

110

Fig. 2 IQ constellation plot of GPS III L1 signals showing the in-phase contribution of the $\mathrm{L} 1 \mathrm{C}+\mathrm{P}(\mathrm{Y})$ signal components and the $\mathrm{C} / \mathrm{A}$ code quadrature component as well as the M-code signal transmitted by a separate antenna chain.

Properties of the individual L1 signal components can best be studied, whenever the M-code transition is closely aligned with the quadrature component of the main L-band antenna signal and can readily be separated from the $\mathrm{L} 1 \mathrm{C}$ and $\mathrm{P}(\mathrm{Y})$ contribution. This is illustrated in Fig. 3, which shows distinct spectra obtained from the I- and Qchannels in such a condition. For the in-phase component (top), two narrow peaks can be recognized next to the center frequency, which are caused by the $\mathrm{BOC}(1,1)$ modulation of the $1.023 \mathrm{MHz} \mathrm{L} 1 \mathrm{C}$ signal. They are superimposed on a ten times wider lobe of reduced amplitude, which originates from the BPSK(10) binary phase shift keying modulation of the $10.23 \mathrm{MHz} \mathrm{P}(\mathrm{Y})$ signal. A completely different pattern is obtained for the quadraturephase components (Fig. 3, bottom), which reflects the contribution of the $1.023 \mathrm{MHz}$ C/A-code. At the same time, the $\mathrm{BOC}(10,5)$ binary offset carrier modulation of the $5.115 \mathrm{MHz}$ M-code with a $10.23 \mathrm{MHz}$ subcarrier is clearly discernible from two broad lobes shifted by about $\pm 10 \mathrm{MHz}$ from the center frequency.

The combination of three components, i.e., L1C data, L1C pilot, and $\mathrm{P}(\mathrm{Y})$, into a single binary signal sequence for the I-channel is accomplished through "interlaced majority voting", also known as "weighted voting". This technique extends the concept of majority voting for multiplexing of signals with time multiplexed interlacing of chips from the two strongest signals (Spilker and Orr 1998; Dafesh and Kahn 2009, Frye 2017). While majority voting alone yields an equal-power combination, the weighted voting scheme can be used to combine the three signals with different effective power level. This is achieved by controlling the fractions of time during which an individual signal is transmitted instead of the combination obtained by a traditional majority voting. 

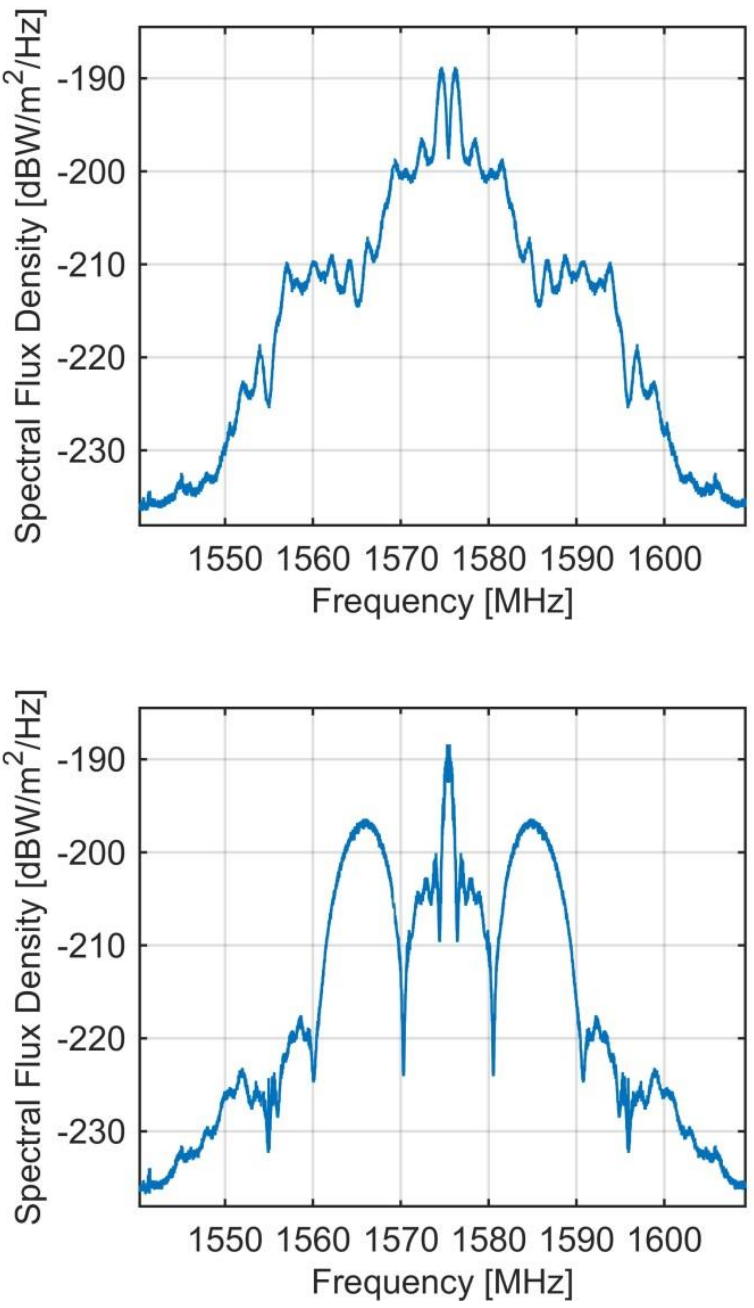

Fig. 3 Spectral contributions of selected GPS III L1C + $\mathrm{P}(\mathrm{Y})$ signal components (top) and $\mathrm{M}+\mathrm{C} / \mathrm{A}$ (bottom).

In case of GPS III, the interface specifications (IS-GPS-200J, IS-GPS-800E) define the minimum received power levels summarized in Table 1. From these, relative power levels of 1.41 and 2.98 can be derived for the L1

$140 \mathrm{P}(\mathrm{Y})$ and L1C-P signals relative to the weakest signal component L1C-D. Using majority voting, a combined signal

$$
s_{\mathrm{MV}}=s_{\mathrm{L} 1 \mathrm{C}-\mathrm{D}}+s_{\mathrm{L} 1 \mathrm{C}-\mathrm{P}}+s_{\mathrm{P}(\mathrm{Y})}-s_{\mathrm{L} 1 \mathrm{C}-\mathrm{D}} \cdot s_{\mathrm{L} 1 \mathrm{C}-\mathrm{P}} \cdot s_{\mathrm{P}(\mathrm{Y})}
$$
with $25 \%$ power sharing for each of the three user signal components and the intermodulation product is obtained.

142 Based on a pseudorandom sequence, the signal generator then toggles between transmission of the $s_{\mathrm{MV}}$ combination 143 and transmission of uncombined $s_{\mathrm{L} 1 \mathrm{C}-\mathrm{P}}$ and $S_{\mathrm{P}(\mathrm{Y})}$ signals for the specified fractions of time. As discussed in Dafesh 144 and Kahn (2009) and Allen et al. (2019), the specified power ratios are achieved by transmitting the majority voting 145 combination for only $68.5 \%$ of the time, while transmitting pure L1C-P or P(Y) signals for averages of $25 \%$ and $146 \quad 6.5 \%$, respectively. 
Due to the unknown $\mathrm{P}(\mathrm{Y})$-code chip sequence and the associated intermodulation product, the interlacing rate and pseudorandom sequence could not be unambiguously identified within the present study. Likewise, it was not possible to independently verify the published power ratios of the $\mathrm{L} 1 \mathrm{C}-\mathrm{D} / \mathrm{P}$ and $\mathrm{P}(\mathrm{Y})$-code components from the collected IQ measurements.

\section{L2 signal components}

On the $\mathrm{L} 2$ frequency, the legacy $\mathrm{P}(\mathrm{Y})$-code and the civil L2C signal are transmitted that had been introduced with the modernized GPS IIR-M satellites along with the military M-code. A simple QPSK modulation is used for the P(Y) and L2C signal, while the M-code is transmitted via a separate antenna chain like on L1. The resulting IQ constellation is illustrated in Fig. 4. In accordance with the $3 \mathrm{~dB}$ difference of the minimum power level specifications in IS-GPS-200J (2018), the L2C transitions have a roughly $\sqrt{2}$ times higher amplitude than the $\mathrm{P}(\mathrm{Y})$ code chips, which corresponds to a $3 \mathrm{~dB}$ difference in power level. The phase orthogonal modulation of the two signals in SVN 74 with L2C lagging L2 $\mathrm{P}(\mathrm{Y})$ by $90^{\circ}$ represents the current default for all L2C capable GPS satellites. It is also indicated through a corresponding status bit of the CNAV navigation message to alert users of a possible transmission of phase aligned L2C and L2 P(Y) signals (IS-GPS-200J 2018).

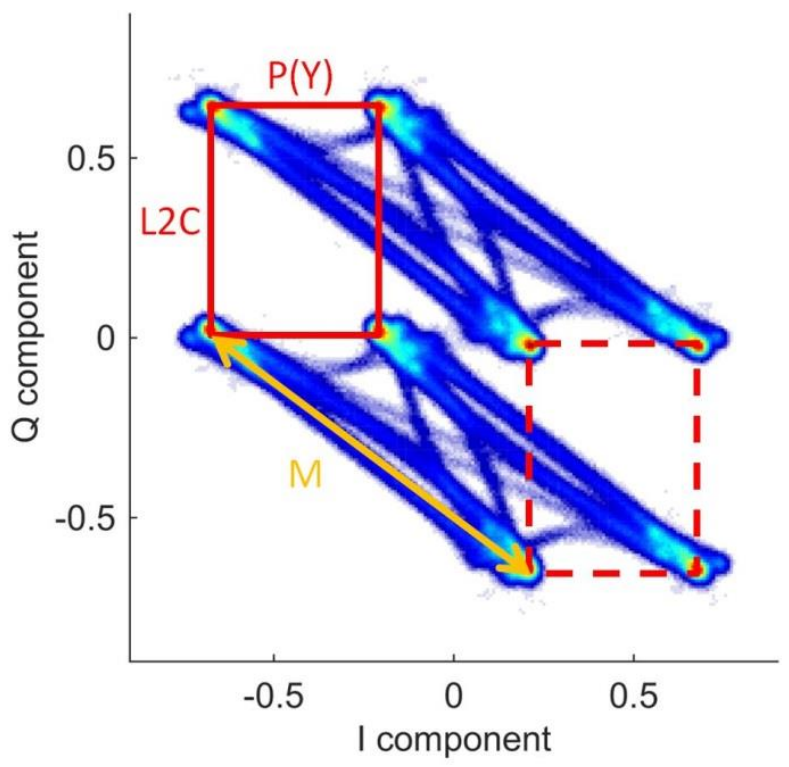

Fig. 4 IQ constellation plot of GPS III L2 signals showing the QPSK modulated L2C and P(Y) signal components as well as the M-code transmitted by a separate antenna chain.

\section{L5 signal components}

The QPSK modulation of the GPS III L5 data and pilot signals with their $10.23 \mathrm{MHz}$ ranging codes matches that of the Block IIF satellites. The IQ constellation diagram shows an extreme purity of the SVN 74 L5 signal compared to previous satellites (Fig. 5), which can be attributed to the use of a mostly digital navigation signal generation unit. 
171 This is further investigated and quantified in the following section.

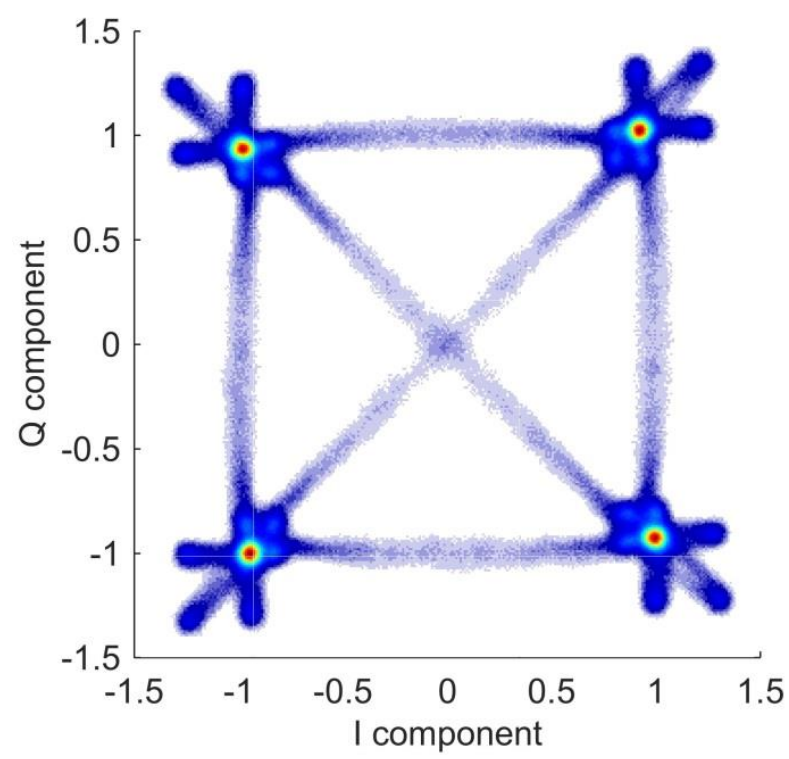

172

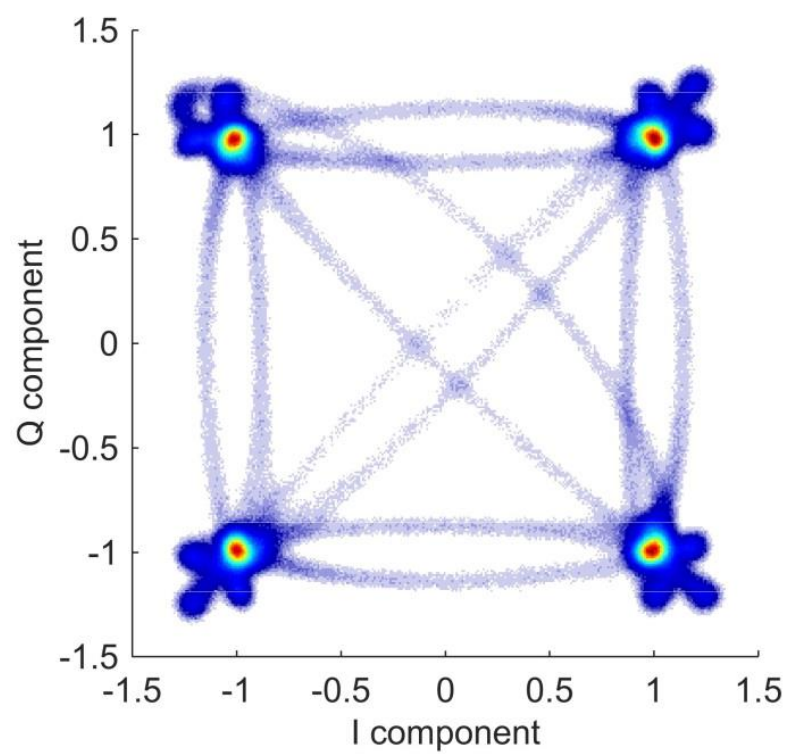

173

174 Fig. 5 IQ constellation plot of the GPS III L5 signal

175 (SVN 74, top) measured on January 9, 09:34 UTC as

176 compared to the GPS IIF-1 satellite (SVN 62, bottom; after

177 Thoelert et al. 2010). 


\section{Signal and measurement quality}

180 Within this section, further analyses of the GPS III signals and the achievable quality of user measurements are 181 presented.

\section{Antenna pattern and signal strength}

183 Using carrier-to-noise density ratio $\left(\mathrm{C} / \mathrm{N}_{0}\right)$ measurements of a GNSS receiver, the received signal strength of GPS III 184 signals can be compared against other satellites in the GPS constellation. For illustration, Fig. 6 shows the variation 185 of $\mathrm{C} / \mathrm{N}_{0}$ with elevation, or, equivalently, transmit boresight angle, as recorded by a reference station near the satellite 186 ground track for SVN 74 and a Block IIF satellite (PRN 9, SVN 68) in the same orbital plane. A third-order 187 polynomial has been fitted to the original $\mathrm{C} / \mathrm{N}_{0}$ values of one satellite pass on February 15, 2019. For the L1 C/A188 code, the Block IIF C/ $\mathrm{N}_{0}$ values are stronger by $2-3 \mathrm{~dB}$ for elevations up to about $35^{\circ}$. Above this elevation, the $\mathrm{C} / \mathrm{N}_{0}$ 189 difference between Block IIF and Block III increases to almost $5 \mathrm{~dB}$. This behavior is also visible in the $\mathrm{P}(\mathrm{Y}) \mathrm{C} / \mathrm{N}_{0}$ 190 curve representing the semi-codeless tracking on $\mathrm{L} 1$ and $\mathrm{L} 2$. The $\mathrm{C} / \mathrm{N}_{0}$ values for $\mathrm{L} 1 \mathrm{C}$ pilot tracking show the same 191 elevation dependence as those for L1 C/A, but are stronger by about $1 \mathrm{~dB}$. Differences of C/ $\mathrm{N}_{0}$ for the L2C and L5 192 signals of the GPS III and GPS IIF satellites are below 0.8 and $1.0 \mathrm{~dB}$, respectively. A notably different shaping of 193 the L1 transmit antenna pattern for the two types of satellites can be inferred from the $\mathrm{C} / \mathrm{N}_{0}$ of L1 C/A and L1C 194 tracking at mid to high elevations. While an M-shaped far-field antenna pattern has been implemented on all GPS 195 satellites starting with Block I to achieve a more uniform received signal power across the entire surface of the Earth 196 (Czopek and Shollenberger 1993), the $\mathrm{C} / \mathrm{N}_{0}$ measurements suggest a notably flatter gain variation of the GPS III L1 197 antenna pattern in the vicinity of the boresight direction as compared to the IIF satellite. 


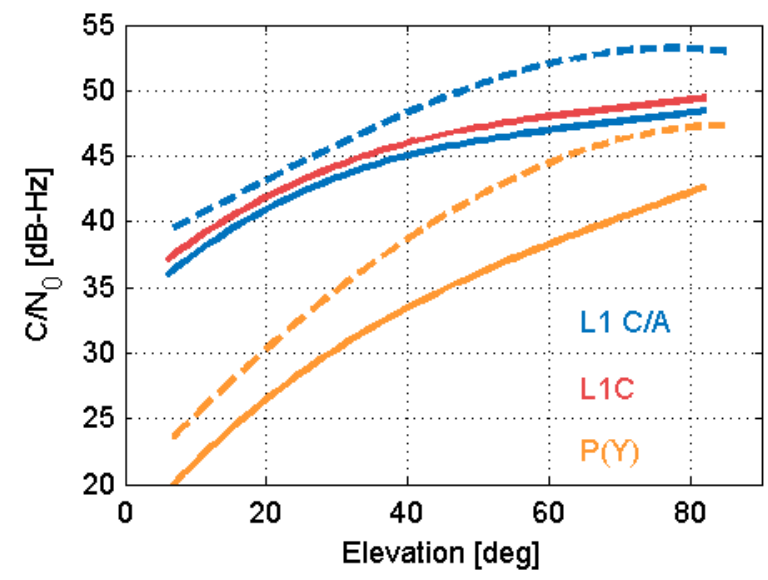

198

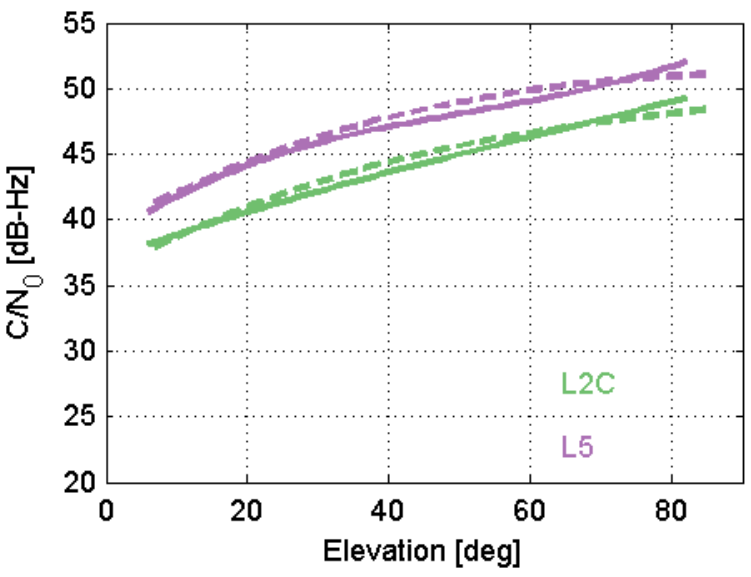

199

Fig. 6 Carrier-to-noise density ratio of GPS signals tracked by a Septentrio PolaRx5 receiver with a Leica AR1203+GNSS antenna in Oberpfaffenhofen, Germany for the first GPS III satellite (solid line) and a Block IIF satellite (SVN 68, dashed line).

Even though the antenna shaping results in mostly smaller $\mathrm{C} / \mathrm{N}_{0}$ values for GPS III-1 than for other GPS satellites, the received power is in full accord with its specification. Based on the calibrated IQ measurements obtained with the high-gain antenna, a ground-received C/A-code power of $-157.9 \mathrm{dBW}$ can be derived for a user observing the SVN 74 satellite at $5^{\circ}$ elevation with an isotropic, circularly-polarized antenna. Within the inherent measurement uncertainty, this value closely matches the minimum received power specified in the GPS signal ICD (see Table 1).

More detailed information on the antenna gain pattern can be obtained from the IQ amplitude of individual L1 signal components (cf. Fig. 2) and their variation with boresight angle as obtained with the Weilheim signal monitoring facility. Results are given in Fig. 7, which shows the equivalent isotropic radiated power (EIRP) for (a) the C/Acode component, (b) the combination of L1C data, L1C pilot, P(Y)-code and their intermodulation product, and (c) 

evidence that the M-code signal originates from a separate antenna chain. Based on the measured M-code transmit power variation over boresight a $3 \mathrm{~dB}$ beamwidth of approximately $\pm 12^{\circ}$ can be obtained.

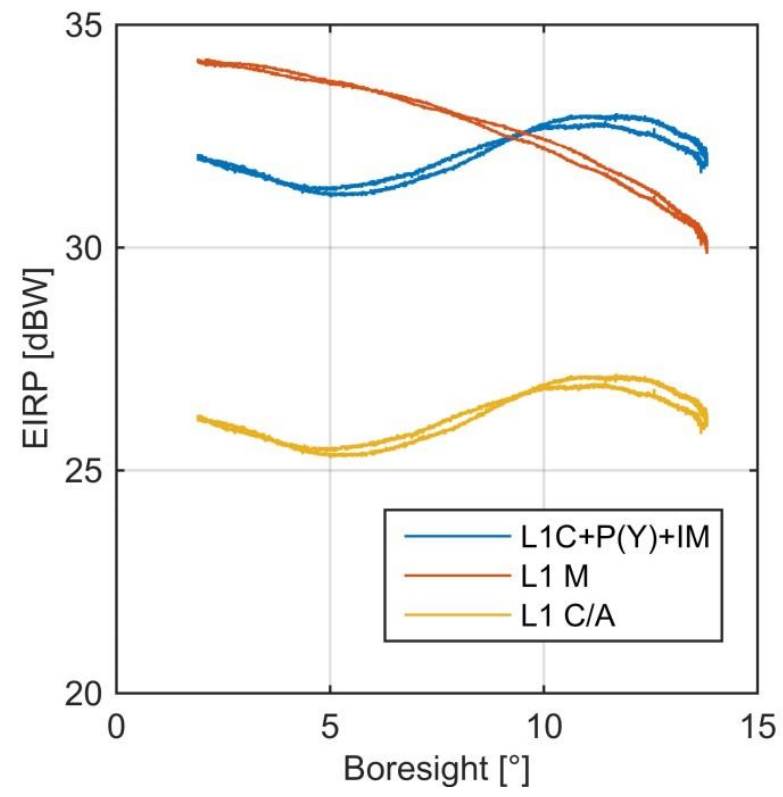

Fig. 7 Variation of the L1 equivalent isotropic radiated power with boresight angle for the C/A-code (yellow), the combination of $\mathrm{L} 1 \mathrm{C}, \mathrm{P}(\mathrm{Y})$, and their intermodulation product (blue), and the M-code signal (red).

\section{Signal distortions and biases}

228 Depending on the characteristics of the satellite's signal generation and transmission payload, GNSS signals are subject to distortions that show up as alterations or imperfections of an ideal chip shape. These affect the correlation process and may cause receiver dependent ranging biases. The impact of nominal signal deformations, i.e. distortions related to the design of the signal generation and transmission chain, rather than specific anomalies, is discussed in Phelts and Akos (2004) as well as Thoelert et.al. (2014) for different GNSSs.

Based on the calibrated IQ data obtained with the $30 \mathrm{~m}$ high-gain antenna, the signal deformations of SVN 74 can be monitored and the impact on the user range estimation can be quantified. To this end, the digitized IQ samples are correlated with an ideal replica of the respective signal using a non-coherent early-minus-late correlator for a pre-selected grid of correlator spacings and filtering bandwidths. The resulting S-curve bias (Soellner et al. 
2008) describes the variation of the resulting tracking point relative to a reference configuration and is a measure of the scatter in ranging measurements obtained with different types of receivers.

In Fig. 8 the S-curve bias for the L1C pilot signal is depicted relative to a reference receiver using a narrow correlator spacing of $\mathrm{d}=0.1$ chips and a two-sided band limitation of $20 \mathrm{MHz}$ in accordance with recommendations in EUROCAE (2019). The result shows a maximum bias of $1 \mathrm{~m}$ that may arise in differential GPS applications using different receiver configurations. For settings which avoid a bandwidth higher than $25 \mathrm{MHz}$ and correlator spacings of less than 0.1 chips, the resulting bias is smaller than $30 \mathrm{~cm}$.

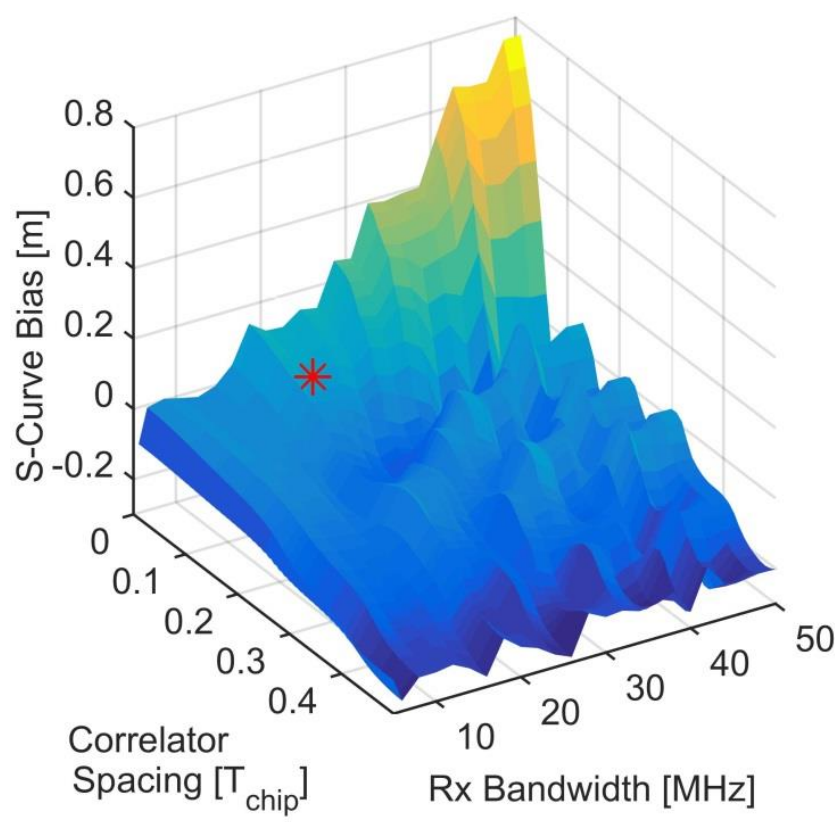

Fig. $8 \mathrm{~L} 1 \mathrm{C}$ code tracking bias as a function of the receiver bandwidth and correlator spacing relative to a two-sided reference bandwidth $\mathrm{B}=20 \mathrm{MHz}$ and correlator spacing $\mathrm{d}=0.1$ chips marked by a red asterisk.

Aside from the new L1C signal, S-curve biases were also derived for the L5 signal. This signal is already transmitted by the GPS IIF satellites and specifically intended for safety critical aviation applications, such as ground based augmentations systems (GBAS) and advanced receiver autonomous integrity monitoring (ARAIM). The textbook-like shape of the L5 IQ constellation diagram of SVN 74 shown in Fig. 5 gives the impression that GPS III users would benefit from lower signal distortions and consequently higher range accuracy. However, this initial impression is not supported by the comparison of S-curve biases for the GPS IIF-1 (SVN 62) and GPS III-1 (SVN74) satellites as shown in Fig. 9. The results are again based on a non-coherent discriminator and cover earlyminus-late correlator spacings of $\mathrm{d}=0 \ldots 1$ chip as well as receiver bandwidths of 5 to $50 \mathrm{MHz}$. For both satellites, range biases relative to a reference receiver with $\mathrm{d}=1$ chip and $\mathrm{B}=24 \mathrm{MHz}$ amount to less than a decimeter for two- 
260 transitions. This shows up in small tails near the stationary points of the IQ diagram (see Fig. 5) that are more 261 pronounced for the new GPS III-1 spacecraft than the IIF-1 satellite.

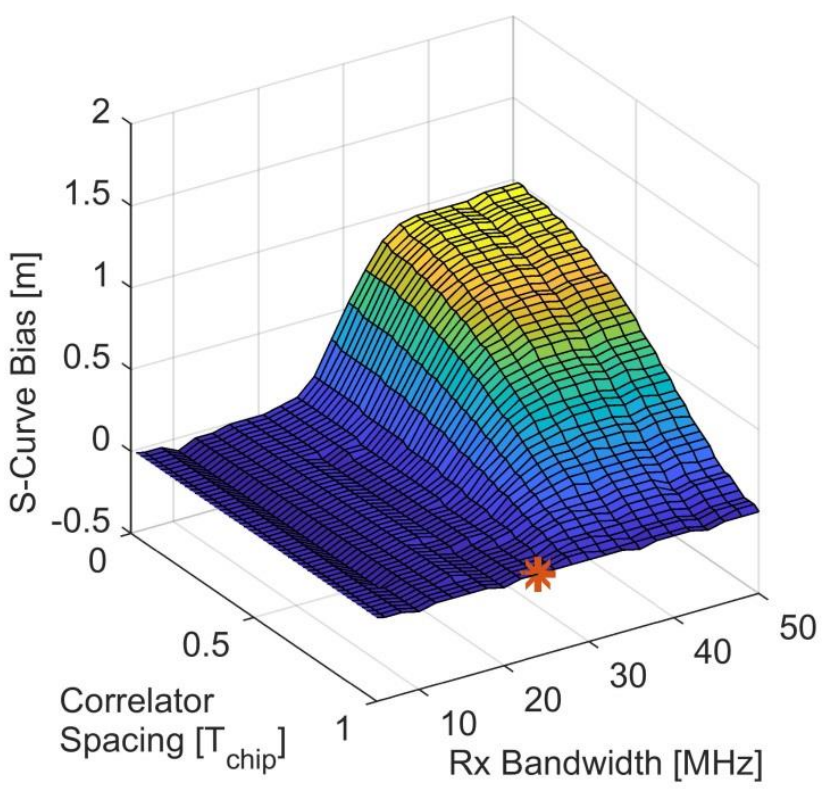

262

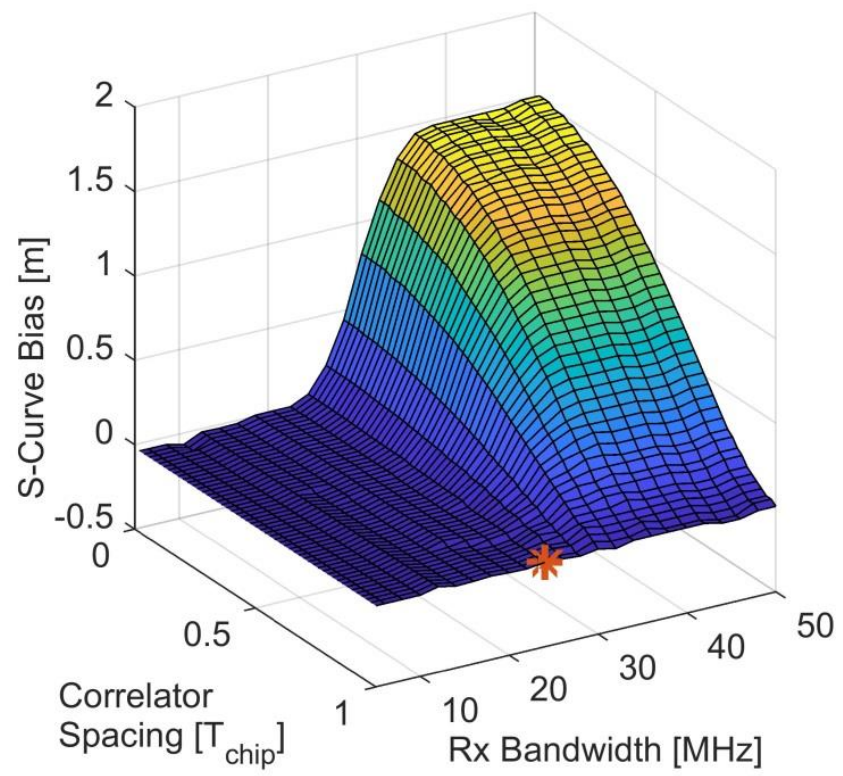

Fig. 9 L5 code tracking bias of a non-coherent discriminator as a function of the two-sided receiver

266 bandwidth and correlator spacing relative to $\mathrm{B}=24 \mathrm{MHz}$ and correlator spacing $\mathrm{d}=1$ chip (red star); example GPS

268 IIF-1 (top), example GPS III-1 (bottom) 

measured IQ data. Digital distortions represent systematic deviations of the chip durations from their nominal values

271 that show up as a lead or lag of the falling or raising edge of the chip. This phenomenon and the associated tracking 272 errors have been widely analyzed for GPS satellites and other GNSSs in view of their relevance for safety critical aviation navigation systems (Phelts and Akos 2006, Thoelert et al. 2014; Vergara et al. 2016).

274 Table 2 Estimated digital distortions for GPS IIF-1 and GPS III-1.

\begin{tabular}{lcc}
\hline & \multicolumn{2}{c}{ Digital distortions [ns] } \\
Signal & GPS IIF-1 & GPS III-1 \\
\hline L5 data & 5.1 & 0.2 \\
L5 pilot & 3.6 & 0.4 \\
\hline
\end{tabular}

Following Vergara et al. (2016), the transfer function of the transmitter chain was determined from highresolution IQ measurements of the L5 signal to remove all analog distortions and to recover the actual digital chip shapes. The resulting digital distortions of the data and pilot components are presented in Table 2 for SVN 74 and a GPS IIF satellite. The comparison shows that the amount of digital distortions within the L5 signal is significantly smaller for the new GPS generation and essentially negligible.

\section{Noise and multipath}

The BOC modulation of the new L1C signal promises reduced thermal measurement noise and multipath sensitivity compared to the legacy L1 C/A code signal. Using the multipath combination (Kee and Parkinson 1994)

$$
\operatorname{MP}\left(p_{i}, \varphi_{i}, \varphi_{j}\right)=p_{i}-\varphi_{i}-2 \frac{f_{j}^{2}}{f_{i}^{2}-f_{j}^{2}}\left(\varphi_{i}-\varphi_{j}\right)
$$

of pseudorange $\left(p_{i}\right)$ and carrier observations $\left(\varphi_{i}, \varphi_{j}\right)$ on two signal frequencies $f_{i \neq j}(i, j=1,2,5)$, the combined noise and multipath of code measurements has been assessed for different signals at the WTZ300DEU reference station of the International GNSS Service (IGS; Johnston et al. 2017, IGS 2019). As shown in Fig. 10, a small error reduction may indeed be noted for the $\mathrm{L} 1 \mathrm{C}$ signal in comparison to $\mathrm{L} 1 \mathrm{C} / \mathrm{A}$ for a wide elevation range, even though L1C is clearly outperformed by the L5 signal with its much higher chipping rate. For the given station, L1C tracking exhibits a slightly lower thermal noise than L1 C/A tracking at identical loop bandwidths which can be related to the increased steepness of the $\mathrm{BOC}(1,1)$ correlator function. Further tests in diverse multipath conditions will, however, be required to assess the practical impact of the additional $\mathrm{BOC}(6,1)$ component in the TMBOC modulated pilot signal. 


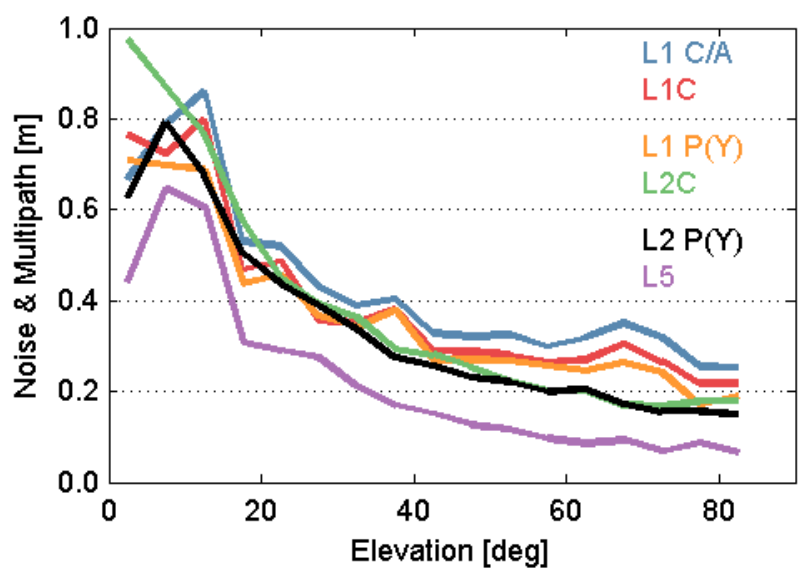

294 Fig. 10 RMS pseudorange noise and multipath of SVN 74 in $5^{\circ}$ elevation bins obtained from a Javad TRE_G3TH receiver at the Geodetic Observatory Wettzell

297 (WTZ300DEU, February 14-16, 2019).

\section{Triple carrier phase combination}

300 Based on triple-frequency carrier phase observations $\varphi_{1}, \varphi_{2}$, and $\varphi_{5}$ the ionosphere- and geometry-free linear combination

$$
\operatorname{DIF}\left(\varphi_{1}, \varphi_{2}, \varphi_{5}\right)=\left(\frac{f_{1}^{2}}{f_{1}^{2}-f_{2}^{2}}-\frac{f_{1}^{2}}{f_{1}^{2}-f_{5}^{2}}\right) \varphi_{1}-\left(\frac{f_{2}^{2}}{f_{1}^{2}-f_{2}^{2}}\right) \varphi_{2}+\left(\frac{f_{5}^{2}}{f_{1}^{2}-f_{5}^{2}}\right) \varphi_{5}
$$

can be formed. This linear combination essentially contains multipath, measurement noise, inter-frequency biases, and biases due to ambiguities. It reflects the difference of satellite clock offsets derived from ionosphere-free L1/L2 and L1/L5 carrier phase combinations and has therefore been designated as inter-frequency clock bias (IFCB) in various studies. Orbit-periodic IFCB variations with amplitudes of up to $20 \mathrm{~cm}$ are present for all Block IIF satellites (Montenbruck et al. 2012) and represent a continued challenge for multi-frequency GPS processing and precise point positioning applications (Pan et al. 2018, Guo and Geng 2018). The observed IFCB amplitude of the IIF satellites depends on the elevation of the Sun above the orbital plane and is smallest for high elevations. 

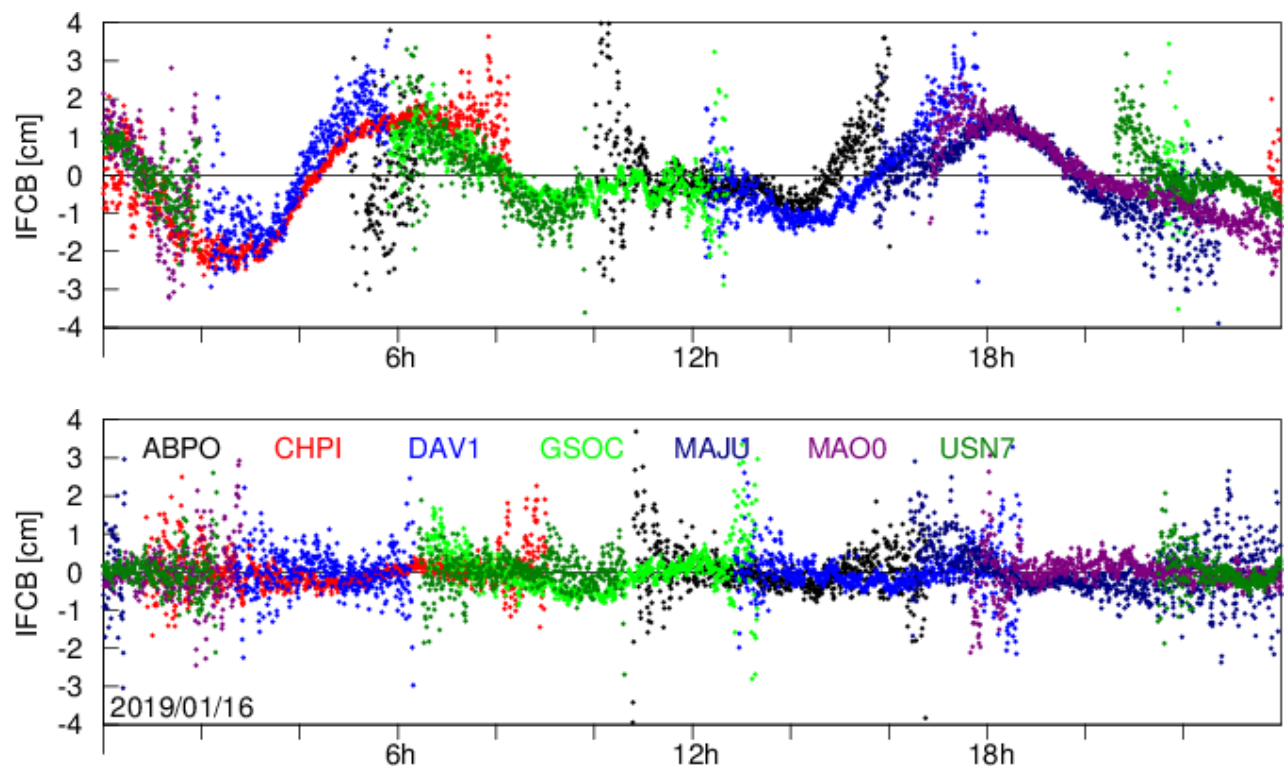

Fig. 11 Inter-frequency clock biases obtained from triple-frequency ionosphere- and geometry-free linear combination for the GPS Block IIF satellite SVN 68 (top) and the Block III satellite SVN 74 (bottom). Orbit-periodic variations can be seen for the Block IIF satellite but not for Block III. Station abbreviations: ABPO: Ambohimpanompo, Madagascar; CHPI: Cachoeira Paulista, Brazil; DAV1: Davis, Antarctica; GSOC: Oberpfaffenhofen, Germany; MAJU: Majuro, Marshall Islands; MAO0: Maui, USA; USN7: Washington, USA.

Fig. 11 shows an ionosphere- and geometry-free carrier phase linear combination for a GPS Block IIF satellite and the new GPS III satellite after removing a bias for each of the seven stations. Carrier phase measurements of the L1 C/A, L2 P(Y), and L5 I/Q tracking have been used (IGS 2019). Both satellites share the same orbital plane F which exhibited a Sun elevation of about $70^{\circ}$ in early 2019. Due to this high elevation, the IFCB variations of the Block IIF satellite are comparatively small, but still clearly visible with a peak-to-peak amplitude of about $4 \mathrm{~cm}$. The SVN 74 spacecraft, on the other hand, does not show such variations, and the triple carrier phase combination is dominated by noise and multipath at low elevations. Based on these measurements, orbit periodic IFCB variations, if present at all, are confined to less than sub-centimeter amplitudes. Further observations will be required, though, to monitor the carrier consistency throughout the annual variation of the orbital plane w.r.t. the Sun.

\section{Summary and conclusions}

332 Following the launch and activation of the first GPS III satellite, the early signals transmitted in January 2019 were investigated using measurements with a high-gain dish antenna and common tracking receivers. Among the novel

334 features of the third generation of GPS satellites is the transmission of the new L1C signal. It includes a 
TMBOC $(6,1,4 / 33)$ pilot signal which is interoperable with other GNSS signals in the L1 band and offers increased robustness and precision for its users. Furthermore, the replenishment of aging GPS satellites by the new GPS III generation will expand the availability of the civil L2C signals as well as the L5 signal for aviation users.

The high-gain antenna measurements clearly reveal the use of an independent transmitter chain for the military M-code signals in the L1 and L2 band. This provides increased operational flexibility and enables M-code power changes without affecting the signal power or phase relation for civil GPS. In the L1 band, a new constantenvelope multiplexing scheme, known as "weighted voting" is employed. It enables the phase coherent transmission of four user signal components, namely the L1 C/A code, the L1C data and pilot codes and the L1 P(Y)-code, on a single carrier. Other than in a traditional majority voting, the power contribution of the individual components can be freely adjusted through randomized interlacing of non-multiplexed signals.

Even though the interlacing scheme and the power rations of the individual L1 constituents could not be investigated based on the high-gain antenna measurements due to the unknown $\mathrm{P}(\mathrm{Y})$-code chip sequence, an L1C pilot power similar to that of the L1 C/A code signal could be confirmed from $\mathrm{C} / \mathrm{N}_{0}$ measurements with GNSS receivers supporting L1C tracking. The observed strength of the civil L1 signals of GPS III is consistent with the specified minimum received power, but falls behind that of the GPS IIF satellites for medium to high elevations due to a notably different shaping of the transmit antenna gain pattern. However, nearly matching signal powers and antenna diagrams were found for the L2 and L5 signals of the two blocks of GPS satellites.

The use of a new digital signal generation in GPS III results in a high purity of chip transitions and IQ constellation diagrams. However, a notable overshooting can still be recognized. As a result, S-curve biases, which describe receiver-dependent variations of the tracking point and limit the achievable quality of differential code corrections are of similar (or even lightly larger) magnitude as for the past GPS IIF generation. Digital distortions, in contrast, show a remarkable reduction to sub-nanosecond level and are essentially negligible in the first GPS III satellite. Also, an excellent consistency of the L1, L2, L5 carrier can be observed with triple-frequency observations and no evidence of thermally induced biases as observed on GPS IIF satellites has been found.

\section{Acknowledgements}

The International GNSS Service (IGS, Johnston et al. 2017) is acknowledged for providing GNSS observation data from their global network of monitoring stations. The authors want to thank their colleagues from the German Space Operations Center (GSOC) for supporting and operating the high-gain antenna at DLR's ground station Weilheim, Germany. 


\section{References}

Allen DW, Arredondo A, Barnes DR, Betz JW, Cerruti AP, Davidson B, Kovach KL, Utter A (2019) Effect of GPS III Weighted Voting on P(Y) Receiver Processing Performance. In: Proc. ION ITM 2019, Institute of Navigation, Reston, Virginia, USA, January 28-31, pp 936-950. https://doi.org/10.33012/2019.16742

Betz JW, Blanco MA, Cahn CR, Dafesh PA, Hegarty CJ, Hudnut KW, Kasemsri V, Keegan R, Kovach K, Lenahan LS, Ma HH, Rushanan JJ, Sklar D, Stansell TA, Wang CC, Yi KS (2006) Description of the L1C Signal. In: Proc. ION GNSS 2006, Institute of Navigation, Fort Worth, Texas, USA, September 26-29, pp 2080-2091

Betz J (2016) Engineering satellite-based navigation and timing - global navigation satellite systems, signals, and receivers. Wiley, Hoboken. https://doi.org/10.1002/9781119141167

Chen YH, Lo S, Enge P, Akos D (2014) Direct Comparison of the Multipath Performance of L1 BOC and C/A using On-Air Galileo and QZSS Transmissions. In: Proc. IEEE/ION PLANS 2014, Institute of Navigation, Monterey, USA, 5-8 May, DOI: 10.1109/PLANS.2014.6851447

Czopek FM, Shollenberger S (1993) Description and performance of the GPS Block I and II L-Band antenna and link budget. In: Proc. ION GPS 1993, Institute of Navigation, Salt Lake City, Utah, USA, September 22-24, pp $37-43$

Dafesh PA, Cahn CR (2009) Phase-Optimized Constant-Envelope Transmission (POCET) Modulation Method for GNSS Signals. In: Proc. ION GPS 2009, Institute of Navigation, Savannah, Georgia, USA, September 22-25, pp 2860-2866

Dafesh PA, Nguyen TM, Lazar S (1999) Coherent adaptive subcarrier modulation (CASM) for GPS Modernization. In: Proc. ION NTM 1999, Institute of Navigation, San Diego, California, USA, January 25-27, pp 649-660

EUROCAE (2019), Minimum Operational Performance Standard for Galileo/Global Positioning System/SatelliteBased Augmentation System Airborne Equipment, ED-259, European Organization for Civil Aviation Equipment, February 2019

FRNP (2017) 2017 Federal Radionavigation Plan, Department of Defense, Department of Homeland Security, Department of Transportation; National Technical Information Service, Virginia, DOT-VNTSC-OST-R-15-01. https://www.navcen.uscg.gov/pdf/FederalRadioNavigationPlan2017.pdf

Frye JR (2017) General interplex technique for signal combining. Navigation 64(1):35-49. https://doi.org/10.1002/navi.179

Guo J, Geng, J (2018). GPS satellite clock determination in case of inter-frequency clock biases for triple-frequency precise point positioning. J Geod 92(10):1133-1142. https://doi.org/10.1007/s00190-017-1106-y

Hegarty CJ, Ross JT (2010) Initial Results on Nominal GPS L5 Signal Quality, In: Proc. ION GNSS 2010, Institute of Navigation, Portland, Oregon, USA, September 21-24, pp 935-942 
Hein GW, Avila-Rodriguez J-A, Wallner S, Pratt AR, Owen J, Issler J, Betz JW, Hegarty CJ, Lenahan S, Rushanan JJ, Kraay AL, Stansell TA (2006) MBOC: The New Optimized Spreading Modulation Recommended for GALILEO L1 OS and GPS L1C. In: Proc. IEEE/ION PLANS 2006, Institute of Navigation, Coronado, USA, 25 27 April, DOI: 10.1109/PLANS.2006.1650688

IGS (2019) International GNSS Service, Daily 30-second observation data, Greenbelt, MD, USA:NASA Crustal Dynamics Data Information System (CDDIS), Accessed 2019/02/18 at https://doi.org/10.5067/GNSS/gnss_daily_o_001

IS-GPS-200J (2018) NAVSTAR GPS space segment/navigation user segment interfaces. Global Positioning System Directorate Systems Engineering \& Integration. 25 April 2018. https://www.gps.gov/technical/icwg/IS-GPS200J.pdf

IS-GPS-800E (2018) NAVSTAR GPS space segment/user segment L1C interface. Global Positioning System Directorate Systems Engineering \& Integration. 25 April 2018. https://www.gps.gov/technical/icwg/IS-GPS800E.pdf

Johnston G, Riddell A, Hausler G (2017) The International GNSS Service. In: Teunissen P, Montenbruck O (eds) Springer Handbook of Global Navigation Satellite Systems. Springer, pp 967-982. https://doi.org/10.1007/978-3$\underline{319-42928-1 \_33}$

Kee C, Parkinson B, Calibration of Multipath Errors on GPS Pseudorange Measurements. In: Proc. ION GPS 1994, Institute of Navigation, Salt Lake City, Utah, USA, September 22-24, pp 353-362

Marquis W, Shaw M (2011) Design of the GPS III Space Vehicle. In: Proc. ION GNSS 2011, Institute of Navigation, Portland, Oregon, USA, September 19-23, pp 3067-3075

Marquis WA, Reigh DL (2015). The GPS Block IIR and IIR-M Broadcast L-band Antenna Panel: Its Pattern and Performance. Navigation 62(4):329-347. https://doi.org/10.1002/navi.123

Montenbruck O, Hugentobler U, Dach R, Steigenberger P, Hauschild A (2012) Apparent clock variations of the Block IIF-1 (SVN 62) GPS satellite. GPS Solut 16(3):303-313. https://doi.org/10.1007/s10291-011-0232-x

Pan L, Zhang X, Li X, Liu J, Guo F, Yuan Y. (2018). GPS inter-frequency clock bias modeling and prediction for real-time precise point positioning. GPS Solut 22:76. https://doi.org/10.1007/s10291-018-0741-y

Partridge MD, Dafesh PA (2001) Code Power Measurement Methodology for GPS Block IIR-M and IIF On-orbit Test Procedures. In: Proc. ION GPS 2001, Institute of Navigation, Salt Lake City, Utah, USA, September 11-14, pp 2764-2772

Phelts RE and Akos DM (2004) Nominal Signal Deformations: Limits on GPS Range Accuracy. In Proc. International Symposium on GNSS/GPS, Sydney, Australia, December 6-8

Phelts RE and Akos DM (2006) Effects of signal deformations on modernized GNSS signals. Journal of Global Positioning Systems 5(1):2-10

Phelts RE, Gao GX, Wong G, Heng L, Walter T, Enge P, Erker S, Thoelert S, Meurer M (2010). Aviation grade: New GPS signals—chips off the Block IIF. Inside GNSS 5(5): 36-45 
Rushanan JJ (2007) The spreading and overlay codes for the L1C signal. Navigation 54(1):43-51. https://doi.org/10.1002/j.2161-4296.2007.tb00394.x

Soellner M, Kurzhals C, Hechenblaikner G, Rapisarda M, Burger T, Erker S, Furthner J, Grunert U, Meurer M, Thölert S (2008) GNSS Offline Signal Quality Assessment. In: Proc. ION GNSS 2008, Institute of Navigation, Savannah, Georgia, USA, September 16-19, pp 909-920

Spilker Jr JJ, Orr RS (1998) Code multiplexing via majority logic for GPS modernization. In: Proc ION GPS 1998, Institute of Navigation, Nashville, Tennessee, USA, September 15-18, pp 265-273

Thoelert S, Erker S, Meurer M (2009) GNSS signal verification with a high-gain antenna - calibration strategies and high quality signal assessment. In: Proc. ION ITM 2009, Institute of Navigation, Anaheim, California, USA, January 26-28, pp 289-300

Thoelert S, Erker S, Furthner J, Meurer M (2010) Latest Signal in Space Analysis of GPS IIF, COMPASS and QZSS. In: Proc. NAVITEC 2010, ESA ESTEC, Nordwijk, The Netherlands, December 8-10

Thoelert S, Vergara M, Enneking C, Antreich F, Meurer M, Brocard D, Rodriguez CS (2014) Characterization of Nominal Signal Distortions and Impact on Receiver Performance for GPS (IIF) L5 and Galileo (IOV) E1 /E5a Signals, In: Proc. ION GNSS+ 2014, Institute of Navigation, Tampa, Florida, USA, September 8-12, pp 31133128

Vergara M, Sgammini M, Thoelert S, Enneking C, Zhu Y and Antreich F (2016) Tracking Error Modeling in Presence of Satellite Imperfections. Navigation 63(1):3-13. https://doi.org/10.1002/navi.129

\section{Biographies}

Steffen Thoelert received his diploma degree in electrical engineering from the University of Magdeburg in 2002. In May 2006 he joined the Institute of Communications and Navigation at DLR Oberpfaffenhofen. His current research activities include signal quality monitoring, satellite payload characterization, system calibration, GNSS compatibility and interference aspects.

Peter Steigenberger received his master and PhD degree in Geodesy from Technische Universität München (TUM) in 2002 and 2009, respectively. Currently, he is senior researcher at DLR's German Space Operations Center (GSOC). His research interests focus on GNSS data analysis, in particular precise orbit and clock determination of GNSS satellites and the evolving navigation systems Galileo, BeiDou, and QZSS.

Oliver Montenbruck is head of the GNSS Technology and Navigation Group at DLR's German Space Operations Center. His research activities comprise spaceborne GNSS receiver technology, autonomous navigation systems, spacecraft formation flying and precise orbit determination as well as new constellations and multi-GNSS processing. Oliver Montenbruck presently chairs the Multi-GNSS Working Group of the International GNSS Service and coordinates the MGEX Multi-GNSS Pilot Project. 
464 Michael Meurer received the diploma in Electrical Engineering and the Ph.D. degree from the University of 465 Kaiserslautern, Germany. Since 2006 he is the director of the Department of Navigation of the German Aerospace 466 Center (DLR). In addition, he is a professor of electrical engineering and director of the Chair of Navigation at the 467 RWTH Aachen University. His current research interests include GNSS signals, GNSS receivers, and navigation for 468 safety-critical applications. 